\section{The effects of compounding discriminative stimuli that control variable-interval limited-hold avoidance*}

\author{
VINCENT M. LoLORDO and CHARLES L. HART $†$ \\ The University of North Carolina, Chapel Hill, N.C. 27514
}

In the presence of either a visual or an auditory discriminative stimulus, but not in their absence, dogs were required to depress a panel to avoid electric shock on a variable-interval limited hold schedule. Once avoidance responding had stabilized, the dogs received presentations of the auditory-visual compound as well as the elements in a test session. All dogs responded at a higher rate in the presence of the compound stimulus than in the presence of either element.

If responding in the presence of either of two discriminative stimuli $\left(\mathrm{S}^{\mathrm{D}} \mathrm{s}\right)$ is reinforced by food on a variable-interval schedule, but responding in the absence of the $S^{D_{S}}$ is extinguished, then summation of responding will occur when the $\mathrm{S}^{\mathrm{D}} \mathrm{S}$ are presented simultaneously. Wolf (1963), Weiss (1964), and others have observed a higher rate of responding in the presence of the independently conditioned $\mathrm{SD}_{\mathrm{S}}$ presented simultaneously than in the presence of either one presented singly. The present experiment extends this finding to instrumental performances maintained by a variable-interval schedule of shock avoidance. A variable-interval schedule was used in order to produce rates of avoidance in the presence of the elements that are comparable to the rates obtained in the appetitive studies cited above. Other studies of summation of avoidance have either used a latency measure (Miller, 1969) or have obtained lower response rates in the presence of the elements than were obtained in the appetitive studies (Emurian \& Weiss, 1972). Thus, given the possibility that the summation of avoidance might be a rate-dependent phenomenon, less likely to occur with high than with low rates in the elements, the present experiment permits direct comparison of response summation in appetitive and avoidance procedures.

\section{METHOD}

The Ss were six male experimentally naive mongrel dogs that were obtained from a local supplier. The dogs were housed individually and maintained on ad lib food and water throughout the experiment. The apparatus was a modification of that described by Black (1958). Each dog was placed in

*This research was supported by Grant MH15468-03 from the National Institute of Mental Health to V.M.L. The authors thank Robert Newlin for his assistance in running several of the animals.

+Now at the Department of Psychology Yale University, New Haven, Conn. 66510 a rubberized cloth hammock; its legs hung down below its body through four holes in the hammock and were secured to metal rings. A yoke was placed over the dog's neck, preventing it from radically shifting its position in the harness, but allowing it to turn its head freely from side to side. The hammock was located inside a sound-reducing booth. The Es and all control and recording equipment were located outside the booth. The manipulanda were two identical rectangular translucent panels, about 12 in. high $\times 8$ in. wide, situated 3 in. laterally to each side of the dog's head. A force of $400 \mathrm{~g}$ was required to close the microswitch mounted behind the panel. Each time the microswitch was closed, a General Electric No. 1820 pilot light bulb mounted behind the panel was turned off for $0.1 \mathrm{sec}$. Shock was delivered through $2 \times 3$ in. brass plate electrodes attached to the footpads of the dog's hind feet. Electrode paste was spread on the plates. A shock of $0-10 \mathrm{~mA}$ could be delivered from a $2,500-5,000-\mathrm{V}$ ac source through a resistance varying from $125 \mathrm{~K}$ to $830 \mathrm{~K}$ ohms in series with the dog. The current was continuously monitored with a milliammeter. One $\mathrm{SD}^{\mathrm{D}}$ was the onset of a 150-W light bulb located $3 \mathrm{ft}$ in front of the dog. The other $S^{D}$ was a $1,300-\mathrm{Hz}$ sine wave tone which was added to the background white noise. The SPL inside the booth was $72 \mathrm{~dB}$ without the CS and $84 \mathrm{~dB}$ with it.

The dogs were first trained to depress either panel once in the presence of an $\mathrm{S}^{\mathrm{D}}$ to escape or avoid electric shock. Half the dogs received the visual $S^{D}$ first, while the other half received the auditory $S^{D}$ first. A panel-press response that occurred in the presence of an $\mathrm{S}^{\mathrm{D}}$ terminated it and avoided the shock. If no response occurred in the first $10 \mathrm{sec}$ of the $\mathrm{S}^{\mathrm{D}}$, the shock began, and $S^{D}$ and shock remained on until a response occurred or the dog received 50 sec of shock. Shock intensity was adjusted for individual dogs to produce effective avoidance, and varied from 5 to $10 \mathrm{~mA}$ across dogs. For a given dog, the shock intensity was constant across $\mathrm{SD}_{\mathrm{S}}$ and also across the last avoidance training session and the test. During the intertrial interval, neither SD was present. Responses that occurred in the intertrial interval, which averaged $90 \mathrm{sec}$ (a rectangular distribution of $60-, 90-$, and $120-\mathrm{sec}$ intervals), had no effect. When a dog made avoidance responses on 10 consecutive trials within a 36-trial session, the second $\mathrm{S}^{\mathrm{D}}$ replaced the first, and the procedure continued until the criterion was again attained. Next, the variable-interval limited hold (VI LH) schedule (Bull \& Overmier, 1968) was introduced and the first $S^{D}$ was again used. Onset of the $\mathrm{S}^{\mathrm{D}}$ on a given trial began the interval, which averaged $3 \mathrm{sec}$ in duration. The first depression of the panel that occurred within $5 \mathrm{sec}$ of the completion of the specified interval caused the $\mathrm{S}^{\mathrm{D}}$ to be terminated and shock to be omitted. If no response occurred within the 5 -sec limited hold period, shock began and a single response terminated $\mathrm{S}^{\mathrm{D}}$ and shock. After the dog made avoidance responses on 10 consecutive trials within a session, the procedure was repeated with the second $S D$. Next the VI value was increased to $6 \mathrm{sec}$, and trials were run until the criterion was met in the presence of each $\mathrm{S}^{\mathrm{D}}$. The procedure was repeated again with a 9-sec VI value. On the day following the last training session, the effects of the compound stimulus were determined. The test session differed from avoidance training sessions in two major respects: (1) each dog received 12 presentations of the visual $\mathrm{SD}, 12$ presentations of the auditory $\mathrm{SD}^{\mathrm{D}}$, and 12 presentations of the simultaneous auditory-visual compound; (2) the avoidance schedule was fixed interval $15 \mathrm{sec}$ and limited hold $5 \mathrm{sec}$, making all test trials roughly the same length. Random selection determined the stimulus to be presented on a given trial, with the restriction that no more than two trials of a given type could occur in succession. Each dog received a unique sequence of trials. The number of responses that occurred on each trial and the duration of that trial were recorded.

\section{RESULTS AND DISCUSSION}

$F$ igure 1 illustrates the median response rate of the six dogs for the 36 trials of the test session. The response rate during the compound discriminative stimulus was consistently higher than the response rate during either element. These group data accurately reflect the behavior of individual dogs, e.g., the mean response rate during the compound $\mathrm{S}^{\mathrm{D}}$ was higher than the 


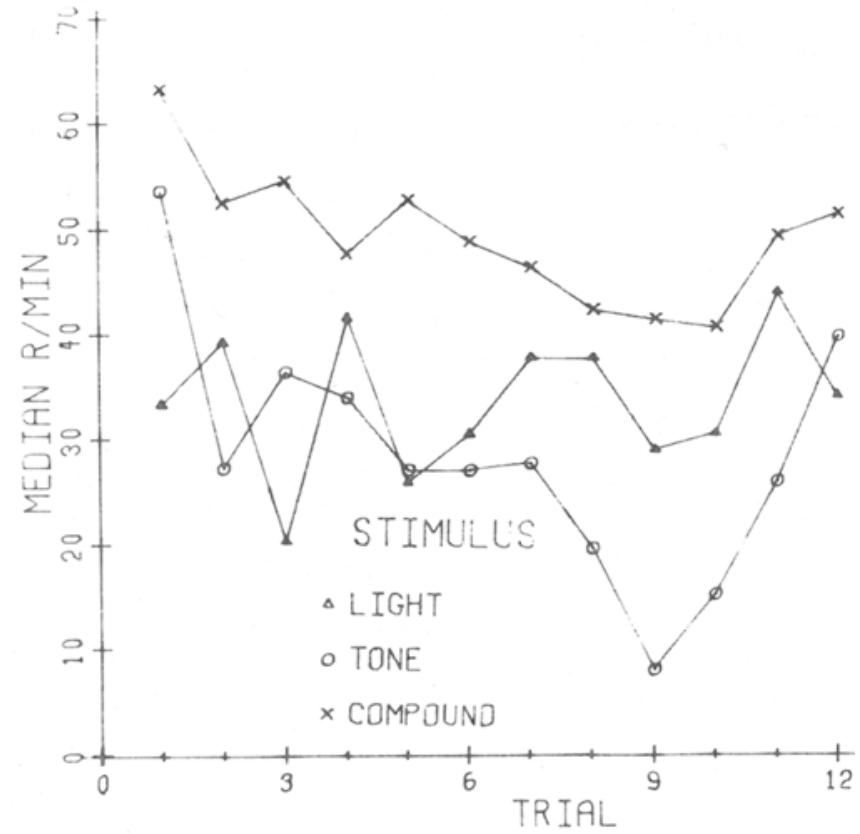

Fig. 1. Median rate of avoidance responding over successive presentations of the visual, auditory, and compound $S^{D}$ s for the group of six dogs. Each dog received a unique sequence of trials.

mean response rate during either element for all six dogs. The magnitude of the summation effect for individual dogs, i.e., the difference between a dog's median response rate in the presence of the compound $S^{D}$ and its median rate in the presence of the elements, tended to be roughly constant despite large individual differences in rate during the elements. Very few responses were made during the intertrial interval.

In the test session, the dogs received a total of only 2 shocks during the light-tone compound, but 7 shocks during the tone and 14 during the light. The occurrence of these shocks was correlated with the increase in response rate observed over the last part of the session and tended to diminish somewhat the difference between the response rates in the compound and those in the elements.
These data indicate that the additive summation obtained with variable-interval schedules of food reinforcement is also found when two $\mathbf{S D}_{\mathbf{S}}$ which independently control a voidance behavior on a VI LH schedule are compounded Summation has also been obtained in two studies of avoidance responding in rats, though not with variable-interval avoidance. Miller (1969) trained rats to cross the midline of a shuttlebox once in either direction to avoid shock. After 80 avoidance training trials with a visual $S^{D}$ and 80 trials with a buzzer, the rats were tested, one trial in eight being a compound of light and buzzer. Three rats which had reached $90 \%$ avoidances to at least one of the $\mathrm{SD}_{S}$ in training had consistently shorter latencies of avoidance in the presence of the compound than in the presence of either element. A fourth rat, which

had avoided on only $25 \%-35 \%$ of the training trials, avoided equally rapidly in the presence of the compound and elements. Emurian \& Weiss (1972) exposed three rats to a three-component multiple schedule in which an unsignaled avoidance procedure (Sidman, 1953) was in effect during either a light or a tone, but not in their absence. In a subsequent extinction test, response rates in the presence of the elements ranged from $1 / \mathrm{min}$ to $12 / \mathrm{min}$ for individual rats. All rats made considerably more responses in the presence of the light-tone compound than in the presence of either element. Summation was also obtained in a subsequent test in which the shock avoidance schedule was in effect in both the compound and elements, though the higher shock rates in the elements somewhat attenuated the compound-element differences in response rate, as in the present experiment. Thus, the response summation effect has been obtained in avoidance studies using different species, responses, and avoidance schedules, and with very different baseline rates of avoidance.

\section{REFERENCES}

BLACK, A. H. The extinction of avoidance responses under curare. Journal of Comparative \& Physiological Psychology, $1958,51,519-527$.

BULL, J. A. III, \& OVERMIER, J B. Additive and subtractive properties of excitation and inhibition. Journal of Comparative \& Physiological Psychology, $1968,66,511-514$.

EMURIAN, H, H. \& WEISS, $S$ J. Compounding discriminative stimuli controlling free-operant avoidance. Journal of the Experimental Analysis of Behavior, 1972, 17, 249-256.

MILLER, L. Stimulus compounding with an instrumental avoidance response. Psychonomic Science, 1969, 16, 46-47.

SIDMAN, M. Avoidance conditioning with brief shock and no exteroceptive stimulus. Science, 1953, 118, 157-158.

WEISS, S. J. Summation of response strengths instrumentally conditioned to stimuli in different sensory modalities. Journal of Experimental Psychology, $1964,68,151-155$.

WOLF, M. M. Some effects of combined S $\mathbf{D}_{\mathrm{S}}$. Journal of the Experimental Analysis of Behavior, 1963, 6, 343-347. 